\title{
BMJ Open Modelling the impact of a smallpox attack in India and influence of disease control measures
}

Biswajit Mohanty, ${ }^{1}$ Valentina Costantino (D) , ${ }^{2}$ Jai Narain, ${ }^{1}$ Abrar Ahmad Chughtai, ${ }^{1}$ Arpita Das, ${ }^{2}$ C Raina Maclntyre (D) ${ }^{2}$

To cite: Mohanty B, Costantino V, Narain J, et al. Modelling the impact of a smallpox attack in India and influence of disease control measures. BMJ Open 2020;10:e038480. doi:10.1136/ bmjopen-2020-038480

- Prepublication history and additional material for this paper is available online. To view these files, please visit the journal online (http://dx.doi.org/10. 1136/bmjopen-2020-038480).

Received 25 March 2020 Revised 10 September 2020 Accepted 04 October 2020
A) Check for updates

(C) Author(s) (or their employer(s)) 2020. Re-use permitted under CC BY-NC. No commercial re-use. See rights and permissions. Published by BMJ.

${ }^{1}$ School of Public Health and Community Medicine, University of New South Wales, Sydney, New South Wales, Australia ${ }^{2}$ Biosecurity Program, The Kirby Institute, University of New South Wales, Sydney, New South Wales, Australia

Correspondence to Dr Valentina Costantino; vale.cost@protonmail.com

\section{ABSTRACT}

Objectives To estimate the impact of a smallpox attack in Mumbai, India, examine the impact of case isolation and ring vaccination for epidemic containment and test the health system capacity under different scenarios with available interventions.

Setting The research is based on Mumbai, India population.

Interventions We tested $50 \%, 70 \%, 90 \%$ of case isolation and contacts traced and vaccinated (ring vaccination) in the susceptible, exposed, infected, recovered model and varied the start of intervention between 20, 30 and 40 days after the initial attack. Primary and secondary outcome measures We estimated and incorporated in the model the effect of past vaccination protection, age-specific immunosuppression and contact rates and Mumbai population age structure in modelling disease morbidity and transmission.

Results The estimated duration of an outbreak ranged from 127 days to 8 years under different scenarios, and the number of vaccine doses needed for ring vaccination ranged from 16813 to 8722400 in the best-case and worst-case scenarios, respectively. In the worst-case scenario, the available hospital beds in Mumbai would be exceeded. The impact of a smallpox epidemic may be severe in Mumbai, especially compared with high-income settings, but can be reduced with early diagnosis and rapid response, high rates of case finding and isolation and ring vaccination.

Conclusions This study tells us that if smallpox reemergence occurs, it may have significant health and economic impact, the extent of which will depend on the availability and delivery of interventions such as a vaccine or antiviral agent, and the capacity of case isolation and treatment. Further research on health systems requirements and capacity across the diverse states and territories of India could improve the preparedness and management strategies in the event of re-emergent smallpox or other serious emerging infections.

\section{INTRODUCTION}

India is the second-most populous country in the world, with several megacities, such as Mumbai, Delhi and Chennai, where people live in close proximity with high population density. Infectious disease epidemics are common in India, such as H1N1pdm09 which

\section{Strengths and limitations of this study}

- The model takes into account heterogeneity of age, disease transmission and immunological levels.

- Age-specific rates of immunosuppressive conditions were estimated for Mumbai and included in the model.

- This study does not include different route of transmission than airborne.

- Other aspects that could influence transmission include seasonality, or vaccination effectiveness such as vaccine refusal were not included in the model.

has been causing recurrent, severe epidemics since 2009. ${ }^{12}$ A study of the phylogeography of influenza H1N1pdm09 in India showed that most transmission around the country was from Maharashtra. ${ }^{3}$ Any respiratory transmissible infectious disease can spread rapidly especially in an urban population. A biological attack caused by a respiratory-transmissible agent such as smallpox could have a serious impact in India, due to high contact rates and population density. ${ }^{4}$ The last natural case of smallpox occurred in 1977, but India was at that time the epicentre of smallpox globally. ${ }^{5}$

Smallpox was declared eradicated globally in 1980, but recent developments in synthetic biology of orthopoxviruses have increased the risk of re-emergence of the variola virus (VARV) ${ }^{6-9}$ Stocks of live VARV are currently held in two WHO collaborating centres in the USA and the Russian Federation, but the virus could be created synthetically. ${ }^{710}$

Before smallpox eradication, nearly $60 \%$ of unvaccinated close contacts or secondary household contacts of smallpox were infected, and airborne transmission was also observed. ${ }^{11}$ India was one of the most challenging settings for the global eradication campaign, which began in 1967 using mass vaccination as a strategy. ${ }^{12}$ India had its first lymph smallpox vaccine in the 19 th century, ${ }^{10}{ }^{13-16}$ and at the beginning of 20th century (1900-1947), many 
research institutes in India started manufacturing smallpox vaccine as lymph. ${ }^{17}$ In the previous century, the 'Government of India Act of 1919' introduced a system of dual government for the British India provinces with the principle of division of executive branch of each provincial government into popularly responsible section and authoritarian section. ${ }^{18} 19$ This resulted in fragmentation of authority, due to transfer of various areas of administration from federal ministers to local-government, including education, agriculture, public works and public health. ${ }^{18} 19$ Local governments were responsible for providing public health programmes, such as smallpox vaccination. ${ }^{17}$ However, insufficient financial support from local authorities to finance vaccination led to low uptake of smallpox vaccination. ${ }^{17}$ Patchy vaccination efforts continued till the start of World War II (1939) and became worse during the war. ${ }^{17}$ World War II led to a further resurgence of smallpox in the period 1944-1945 in India. ${ }^{17}$ However, an increased focus on smallpox vaccination after the war resulted in a decrease in cases. ${ }^{17}$ Due to the inability to achieve high coverage with mass vaccination in India, the WHO made the decision to change from mass vaccination to 'surveillance contaminant searching' and ring vaccination first in Africa, followed by India; this thereafter became the mainstay of the global eradication strategy. ${ }^{1720}$ Ring vaccination strategy limits the spread of disease by vaccinating close or direct contacts of diagnosed cases, who are most likely to be infected. ${ }^{21}$

Smallpox is a highly infectious disease, which can be caused by two different variants, variola minor and variola major. The first presents with much milder symptoms and a case fatality rate (CFR) of about $1 \%$, while variola major had a CFR greater than $30 \%{ }^{22-24}$ and the risk of death higher among infants, ${ }^{25} 26$ older people ${ }^{27}$ and the immunosuppressed. The impact of smallpox reemergence is affected by residual vaccine immunity and immunosuppression. ${ }^{28}$ Smallpox vaccine immunity wanes over time, possibly as rapidly as within 5 years. ${ }^{29} 30$ People with multiple primary vaccinations may have greater protection, up to $10-20$ years or longer. ${ }^{31} 32$ However, it is unclear how long protection lasts after multiple vaccinations. Nearly 40 years since mass vaccination programmes ceased, residual vaccine immunity is likely to be minimal. ${ }^{31}{ }^{32}$ Routine smallpox vaccination has not occurred in India since eradication was declared in $1980 .{ }^{29}$ Population immunity in India is therefore likely to be low. There has been limited research on population-level smallpox immunologic status and residual vaccine immunity in India. Furthermore, health capacity in India in the event of resurgent smallpox will be a challenge in remote, rural and urban settings, as well as in coordinating public health response across a largely privatised health sector. ${ }^{33}$

\section{Aims}

The aim of this study is to estimate the impact of smallpox re-emergence in Mumbai, India under different scenarios with available interventions.

\section{METHODS}

The scenario is a deliberate, large scale attack, with 1000 cases of smallpox occurring simultaneously in Mumbai. A large scale attack was used to test the worst case scenario. We assumed that the virus used in the biological attack is variola major, therefore the circulation of variola minor is not considered in this analysis.

We used a susceptible, exposed, infected, recovered model for smallpox transmission ${ }^{28} 3435$ to simulate a smallpox outbreak in Mumbai. The model assumes an overall rate of transmission from person to person based on observed epidemiology as described below, but does not differentiate modes of transmission (such as airborne, fomite or contact).

In the model, the population was categorised into vaccinated and unvaccinated compartments and these compartments were further split into severely immunosuppressed, mildly immunosuppressed and immunocompetent groups. The model contains ordinary differential equations to shift the population into different epidemiological transmissible states such as susceptible, infected, infectious, recovered and dead. ${ }^{27}$ Susceptible and latent compartments in the model are a matrix of 6 rows and 18 columns, where the rows represent the different immunity levels or disease severity and the columns are the age groups, while the infectious compartment is a matrix of 4 rows and 18 columns, representing smallpox disease types and age groups, respectively. ${ }^{27}$

Mumbai was selected because transmission studies of influenza (also transmitted by the respiratory route, such as smallpox) show it to be the epicentre of respiratory transmission. ${ }^{3}$ We then simulated outbreak response in order to explore the duration of the epidemic, vaccination doses needed and required health capacity system in Mumbai. Vaccine efficacy pre-exposure was estimated and reported from WHO as between $91 \%$ and $97 \%$ for first-generation vaccines, used in the pre-eradication era, while the second-generation vaccines, stockpiled now in most countries, has an estimated efficacy between $96 \%$ and $99 \% .{ }^{36}$ In this study, we assumed a vaccine efficacy of 95\% and $98 \%$ for people never vaccinated and previously vaccinated, respectively. In the case of vaccine as postexposure prophylaxis for contacts, we halved the efficacy to $50 \%$ and $53 \%$, respectively.

We estimated the total vaccine doses required and the number of hospital beds required for both best and worstcase scenarios. The number of doses were compared with the available WHO stockpile of smallpox vaccine ${ }^{37}$ in order to determine whether the stockpile is sufficient to control the epidemic in Mumbai. We also determined the duration of the epidemic under different scenarios. The number of hospital beds were compared with the available beds in Mumbai ${ }^{33}$ to identify in which scenario the beds would be insufficient.

The model accounts for different infectivity and susceptibility for immunocompromised and healthcare workers (HCWs). ${ }^{28} 34$ The population data and contacts rates for Mumbai, to inform the model, were estimated as follows. 
Model diagram, differential equations and all parameters used (see online supplemental table 1) are listed in the online supplemental material 1.

\section{Population, healthcare workers and hospital beds}

We used an estimated total population for Mumbai, India in $2019,{ }^{38}$ with age distributed following the age-specific percentages of Mumbai population. ${ }^{39}$ The model uses 18 age groups, 5-year wide up to 84 years old with an additional age group, $85+$ years. We estimated the number of HCWs in India, consisting of physicians, nurses and midwives, who accounted for $0.29 \%$ of the total Indian population in 2015 and used this estimate for Mumbai population. ${ }^{40}$ To distribute the HCWs across age groups, we used the age distribution of nurses in Mumbai, ${ }^{41}$ as they represent the biggest part of the HCW population. We estimated the number of hospital beds in Mumbai, and the proportion of beds in private hospitals using available data sources. ${ }^{42} 43$

\section{Contact matrix}

We used an estimated age-specific contact matrix for India. ${ }^{4}$ The matrix is represented in 5-year age group starting from 0 to 4 years old to $70-74$ years old and the rest of the contacts are presented in one upper age group (75+ years). ${ }^{4}$ Since our model uses a 15 age-group contact matrix and the India matrix is available in 16 age groups, we took the mean of the last two age groups and fitted 15 age group contact rates in the model (see online supplemental table 2). ${ }^{427}$

\section{Previously vaccinated population}

We assumed that about $70 \%$ of the population in 40-69 years age group in India (born before 1977) were previously vaccinated (see online supplemental table 3 ), ${ }^{17}$ considering the fact that smallpox was epidemic in India in $1974^{44}$ and a higher proportion of Indian populations born before 1977 are vaccinated. ${ }^{20}$ We considered vaccination had stopped in India after 1977 since the last case of smallpox in India was seen in May $1975^{20}$ and India was declared free from smallpox in $1977 .{ }^{17}$ The immunity against smallpox wanes $1.41 \%$ per year after vaccination. ${ }^{27}{ }^{30}$ Using this rate of waning, we calculated the age-specific residual protection by multiplying $1.41 \%$ with the number of years from vaccination and then subtracted from $100 \%$ effectiveness, for vaccinated people 40-69 years. ${ }^{27}$ We considered that vaccine immunity wanes over time and people vaccinated prior to 1980 and now aged $>69$ years have zero residual immunity against smallpox. ${ }^{27}$

\section{Immunosuppressed population}

A minimum estimate of immunosuppression in India was made using HIV infection, cancer chemotherapy, steroid treatment for asthma and chronic obstructive airways disease, organ transplantation and autoimmune diseases, using a previously published method for estimating immunosuppression. ${ }^{27}$ The total patients with HIV in India was estimated to be 2.14 million in 2017, which is $0.1597 \%$ of the total population. ${ }^{45}$ We used an estimated age-specific distribution from $2009 .^{46}$ However, this study divides the HIV prevalence in only three age-groups, which we further divided equally for our 18 age groups. We estimated the cancer prevalence to be $0.08391 \%$ in India in $2015 .{ }^{47}$ We distributed this across age groups in the model using age-specific cancer prevalence data from $2014 .{ }^{47}$ Around 7715 solid organ transplants were made in India in $2015^{48}$ representing $0.00058938 \%$ of the total population. We have used age-specific transplants distribution estimated for the US population, as Indian data were not available. ${ }^{49}$ Asthma and chronic obstructive pulmonary disease (COPD) were estimated to be $5.47 \%$ and $1.30 \%$ of the total Indian population in 2015. ${ }^{50} 51$ However, most patients in India would not receive oral or inhaled corticosteroids compared with a high-income country, therefore we assumed one-third of asthma and patients with COPD that is, $1.82 \%$ and $0.43 \%$, respectively would be treated with corticosteroids. We estimated the number of people with asthma and COPD for the given age groups and divided equally for 5-year age groups, respectively, and then estimated the prevalence percentage with respect to the population in that age group. Persons living with autoimmune diseases in India are estimated to be $7.96 \%$ of the total population. ${ }^{52-59}$ As most people in India with the autoimmune disease would not have access to immunosuppressive drugs, we assumed one-third of the total, that is, $2.65 \%$ of people would be treated with immunosuppressive drugs. We distributed this prevalence using the average age-specific distribution estimated from Spain and the US rheumatoid arthritis incidence. ${ }^{60} 61$ They divide the incidence into seven age groups over the entire population, which we adapted to 18 age groups. Accordingly, the model was fitted with the immunosuppressed proportion estimated for India adjusted to the Mumbai population.

\section{Smallpox disease types}

Once infected we assumed four different types of disease for smallpox: vaccine-modified, ordinary, flat and haemorrhagic smallpox. We assumed that each disease type has a different infectivity (R0), a different CFR and a different age distribution rate depending on the immunological status of the infected person, as outlined in our previous study and in online supplemental table $6 .{ }^{34}$ Infection with haemorrhagic and flat smallpox have the highest infectivity with $\mathrm{R} 0=10^{62}$; however, we used an $\mathrm{R} 0=5$ to account for the isolation of severely ill patients. For ordinary smallpox, we assumed $\mathrm{R} 0=7.96$, estimated from a detailed study of an outbreak in Nigeria in an unvaccinated community, ${ }^{63}$ and for modified smallpox, we assumed R0=5.3 (2/3 of the R0 estimated for the ordinary type). Because of milder symptoms, we accounted for isolation and halved $\mathrm{R} 0$ from the third and fourth day for ordinary and modified smallpox, respectively.

Data from historical outbreaks ${ }^{31}{ }^{64}$ shows that persons infected with haemorrhagic, flat and vaccine-modified smallpox have a CFR of $100 \%-95 \%, 90 \%$ and $0 \%$, respectively, while for ordinary smallpox, infection is 

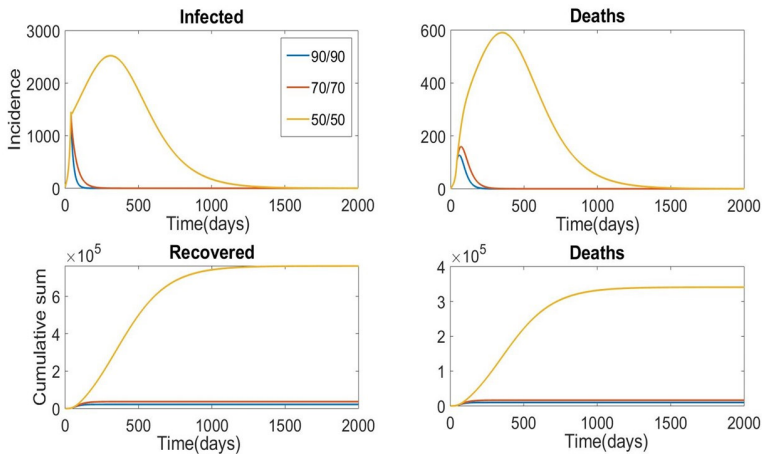

Figure 1 Epidemic response for 1000 initial attack at a fixed time of intervention $\mathrm{T}=40$, with $90 \%, 70 \%$ and $50 \%$ of cases isolated and contacts traced and vaccinated.

age-specific. ${ }^{31}$ In our study, to take into account better access to healthcare, we assumed the same CFR for ordinary and vaccine-modified smallpox, but a slightly lower CFR for haemorrhagic and flat cases, being $90 \%$ and $75 \%$, respectively. All CFRs are shown in the online supplemental material 1.

Distribution rates of each disease type for healthy unvaccinated people are derived from available data from Rao study ${ }^{31}$ by linear interpolation of the available age groups. While for severe immunosuppressed we assumed them to have only haemorrhagic smallpox, for mild immunosuppressed people we doubled the rates of haemorrhagic and flat estimated for healthy unvaccinated people. For the previously vaccinated subgroup we estimated $25.3 \%$ of vaccinated persons get vaccine modified smallpox ${ }^{31}$ and we applied a waning immunity rate of $1.41 \%$ per year following vaccination. ${ }^{65}$ Age-specific rates of each disease by immunity level are shown in the online supplemental material 1.

\section{Sensitivity analysis}

A sensitivity analysis conducted on the number of initial infected, percentage of case isolation and of contacts vaccinated and time to starting the response (see online supplemental table 4 ). We varied the initial attack size between 50 and 100000 to determine the effect of the epidemic without intervention in Mumbai. The total recovered, infected and death rates were estimated for Mumbai for several scenarios. We tested $50 \%, 70 \%, 90 \%$ of case isolation and contacts traced and vaccinated (ring vaccination). We varied the start of intervention between 20, 30 and 40 days after the initial attack. We defined 'epidemic control' as being able to reduce the daily number of new infected per infectious person, so in this study, an epidemic is defined under control when the infectious incidence is decreasing and we estimated the critical threshold proportion of case and contacts to be isolated and traced, respectively, to be able to reduce transmissions. ${ }^{9}$ The threshold value was also estimated at which epidemic control is lost ${ }^{9}$ through simulation of the model at values between $50 \%$ and $60 \%$ of case isolation and contact vaccination.

\section{Patient and public involvement}

Patients and/or the public were not involved in the design, or conduct, or reporting or dissemination plans of this research.

\section{RESULTS}

The population of Mumbai is over 20 million. Mumbai has a very young population compared with developed countries, with $83 \%$ of the total population aged between 0 and 49 years, ${ }^{38} 39$ which is the age group with the highest transmission rates. ${ }^{8}$ We estimated 58537 HCWs in Mumbai. We estimated there are $40000+$ hospital beds in Mumbai, with $50 \%$ of those beds in private hospitals.

\section{Immunosuppressed population}

We estimated a rate of $5.14 \%$ immunosuppression in India, with a higher percentage of immunosuppressed people in the 50+ age group (see online supplemental table 5) and the highest immunosuppression observed in persons $85+$ years old.

\section{Impact of response time and interventions}

For a fixed number of 1000 initial infected by the attack, with the best case scenario of $90 \%$ of contacts vaccinated and isolation of $90 \%$ of infectious cases (figure 1), at time to starting interventions of day 40 after the attack, the infectious incidence peaks at 1456 people and it takes over 176 days, respectively, to contain the epidemic. On day 40 of intervention, a total of 22040 people will be infected, with a corresponding increase in required vaccine doses (table 1). A total of 2319 deaths by day 50,7646 deaths by day 100 and 9472 deaths by day 150 will be observed when the intervention starts on day 40 .

Figure 1 shows that as rates of case isolation and contact vaccination fall, the epidemic becomes more severe, with a large difference between $70 \%$ and $50 \%$ rates. If ring

Table 1 Vaccine doses required for epidemic control with varying \% of case isolated and \% contacts traced and vaccinated

\begin{tabular}{|c|c|c|c|}
\hline \multirow[b]{2}{*}{$\%$ cases isolated and vaccinated } & \multicolumn{3}{|c|}{ Doses needed with time of intervention (' $T$ ' in days) } \\
\hline & $T=20$ & $\mathrm{~T}=30$ & $\mathrm{~T}=40$ \\
\hline 90/90 & Doses=16 813 & Doses=37 092 & Doses=82 486 \\
\hline 70/70 & Doses $=27341$ & Doses=60 654 & Doses $=135100$ \\
\hline $50 / 50$ & Doses $=2228600$ & Doses $=2336600$ & Doses $=2548800$ \\
\hline $30 / 30$ & Doses $=8718800$ & Doses=8 720000 & Doses=8 722400 \\
\hline
\end{tabular}




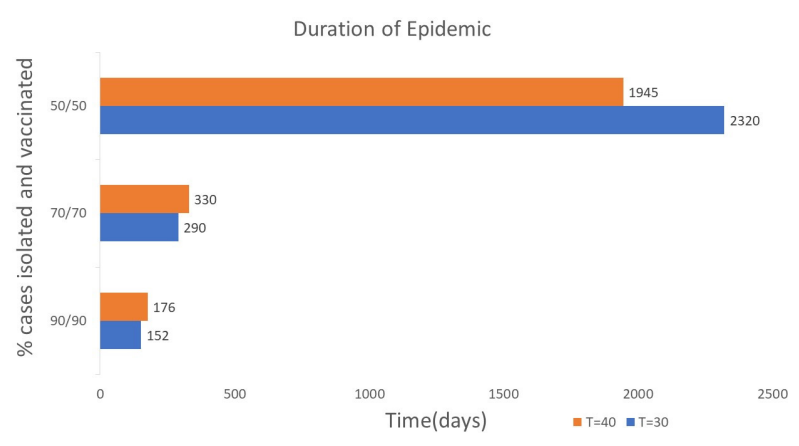

Figure 2 Epidemic duration with varying contact vaccination and case isolation rates.

vaccination and isolation decreases to $50 \%$ of the contacts and cases, respectively (figure 1), the epidemic is more severe resulting in a very high infected and death rates with a very long period of the epidemic and a total of 761 900 people infected. The large difference between the two scenarios such as case isolation and degree of vaccination at $70 \%$ and $50 \%$ rates compared with $90 \%$ and $70 \%$ suggests that epidemic control is lost somewhere between $70 \%$ and $50 \%$.

The epidemic impact was also examined at varying proportions each of case isolation and ring vaccination. With a decrease in the percentage of case isolation and vaccination, the infection and deaths incidence increase and the epidemic takes longer to control.

\section{Duration of epidemic}

Figure 2 illustrates the time to control the epidemic in Mumbai by varying rates of case isolation and ring vaccination, with initial attack size of 1000 infected people. The epidemic will end in less than half a year at $90 \%$ case isolation and ring vaccination rate, and, within 1 year at $70 \%$ of each rate. However, if the rates are $50 \%$ each, the epidemic will continue for more than 6 years, as shown in figure 2.

\section{Vaccine doses}

A total of 16813,37092 and 82486 vaccine doses will be needed with $90 \%$ of each case isolation and ring vaccination, at time of intervention on day 20,30 and 40, respectively. However, at $50 \%$ of each rate, a maximum of 2228600,2336600 and 2548800 vaccines are needed at time of intervention on day 20,30 and 40, respectively (table 1). Vaccine requirements for epidemic control more than double with every 10 days of delay in intervention at higher case isolation and vaccination $(70 \%$ or $90 \%)$.

\section{Hospital beds}

Figure 3 shows the maximum number of beds that will be needed in Mumbai by case isolation and contact vaccination rates, and time of starting interventions, for an attack size of 1000 . The required hospital beds more than double with every 10 days of delay. In all the above cases, at the initial attack size of 1000 , the maximum beds required do not exceed the total available hospital beds of Mumbai

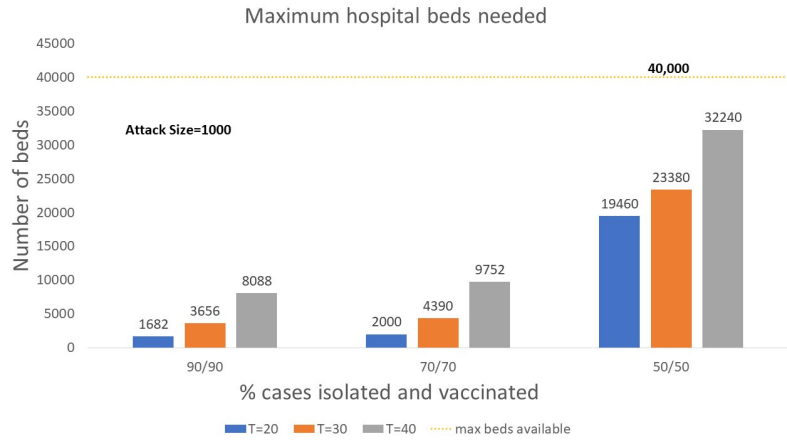

Figure 3 Maximum hospital beds needed under scenarios of different case isolation and contact vaccination rates, by time to response, for an attack size of 1000 .

(40 000 beds). However, in the worst case, almost all beds will be used just for smallpox cases. Figure 4 shows that if the attack size is 10000 , available beds will be exceeded in almost all scenarios.

The threshold initial attack size found to be 5000 (at time of intervention $T=40$ ) above which the number of hospital beds needed exceeds available beds in Mumbai at $90 \%$ case isolation and $90 \%$ vaccination.

\section{Mixed scenario}

When the base case input parameters were used, with 1000 initial infected starting interventions after 30 days and assuming that $70 \%$ of cases presenting symptoms get isolated, reducing the contact traced percentage to $30 \%$ and 20\%, the epidemic can still be controlled with 216 790 and 981310 vaccination doses used, resulting in 55 402 and 380584 deaths, respectively. However, in the case of only $10 \%$ of contacts traced for infected person, the epidemic is not controlled ending with 1082121 deaths using 1337100 vaccination doses. The results are shown in figure 5 .

\section{DISCUSSION}

In the event of re-emergent smallpox in Mumbai, there are several approaches to mitigating the impact, which will be proportional to the size of the attack. Transmission of infection would be intense because Mumbai has high population density, a young population age

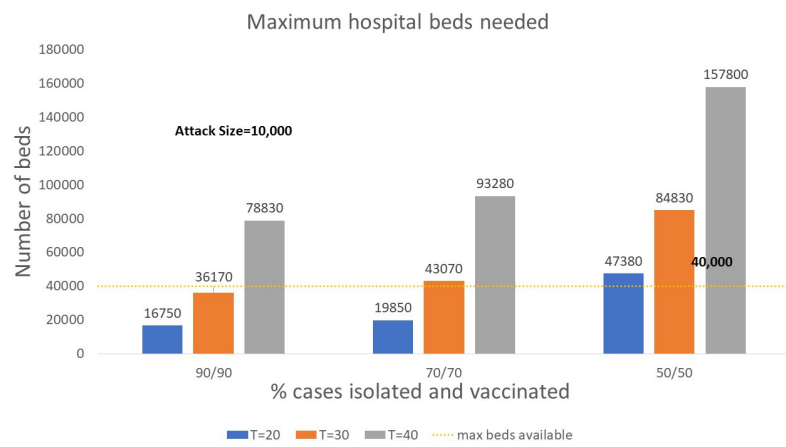

Figure 4 Maximum hospital beds needed under scenarios of different case isolation and contact vaccination rates, by time to response, for an attack size of 10000 mixed scenario. 

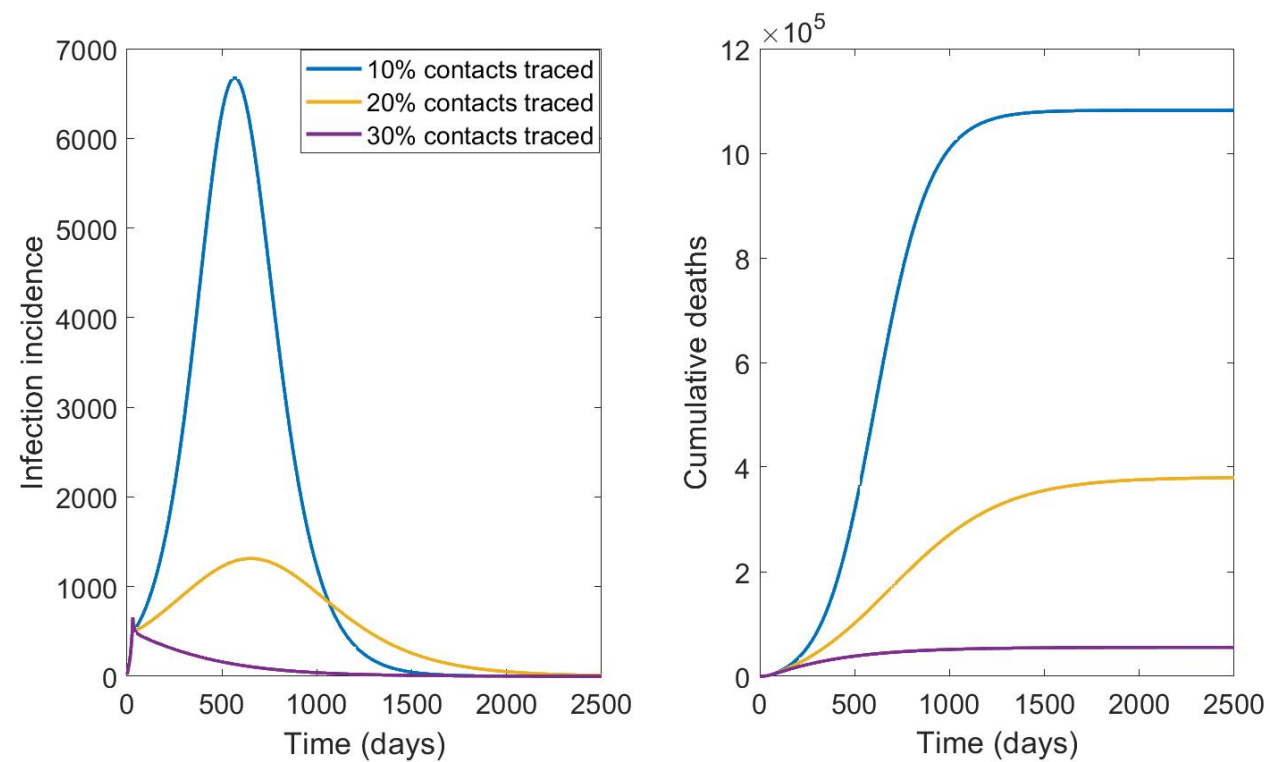

Figure 5 Epidemic curve in the scenario with 1000 initial infected, starting intervention at $\mathrm{T}=30$, assuming $70 \%$ of symptomatic people will get isolated and varying the percentage of contacts traced as $10 \%, 20 \%$ and $30 \%$. Number of new infected symptomatic over time (left) and cumulative number of deaths (right).

structure, coupled with higher contact rates among younger people. ${ }^{46}$ Smallpox has a mean incubation period of 12 days, so that starting vaccination and case isolation at day 20 means, in reality, starting the response 8 days after the first case becomes symptomatic, which, even in the best-resourced country, would be a challenge. It is also likely that the diagnosis may be delayed, given the unfamiliarity of current clinicians with smallpox and many examples of missed or delayed diagnoses of serious infections, such as Ebola, Middle East Respiratory Syndrome (MERS) coronavirus and smallpox. ${ }^{67}$ Every 10 days of delay results in a worsening epidemic. However, diagnosing smallpox may not be that difficult given it is a typical clinical presentation including the centrifugal distribution of the rash, high fever, ocular complications.

Rapid response will depend on early diagnosis, availability of vaccine stockpiles, as well as physical and surge capacity including human resources for isolating infectious cases, tracking contacts and managing the epidemic. The influential predictors of epidemic size are initial attack size, time to start of the intervention, residual vaccine immunity and percentage of cases isolated, contacts traced and vaccinated. While the initial attack size is not within our control, factors that can be controlled include rapid response, high case isolation and high rates of contact tracing and vaccination. Achieving high case isolation and vaccination rates in Mumbai is critical, as failure to do so will increase the epidemic test the health system capacity. In scenarios with a delayed response, low case isolation and vaccination rates, the duration of the epidemic may be more than 6 years.

Due to high density and contacts number, a smallpox outbreak could infect hundreds of thousands of people in Mumbai in a very short time and, unless it is quickly controlled, it can easily spread to the rest of India and globally. This work shows the importance of rapid response, which includes vaccination, contact tracing and case isolation.

The already overstretched health infrastructure with respect to available healthcare workforce, hospital beds and health system capacity in a metropolitan area with a population over 20 million will be tested during any serious epidemic. There are over 40000 hospital beds in Mumbai, with about $50 \%$ of these beds in private hospitals. ${ }^{3342}$ The total available beds in Mumbai would not be exceeded in the best-case scenario, when the initial attack size is 1000 and the case isolation and vaccination is high. However, all scenarios will require surge capacity, and will affect the ability to provide care for other non-smallpox illness. With low case isolation or vaccination, or a large attack size, the maximum beds required will exceed the entire capacity very early in the epidemic. Given the large private hospital sector in India, coordination of pandemic planning with private hospitals may be important. India has a more privatised health system than many other countries, with at least $70 \%$ of care provided in the private sector. ${ }^{68}$ This is a challenge not just for epidemic control, but also for establishing representative disease surveillance across both public and private sectors.

The re-emergence of infectious diseases is a real possibility, not just due to synthetic biology and genetic engineering, but also due to laboratory accidents. In September 2019, a gas explosion occurred in one of the two sites known to house variola, The Russian State Research Centre of Virology and Biotechnology building (Vector) in the city of Koltsovo. ${ }^{69}$ Despite Russian government denials, there was a real risk of the aerosolized virus being propagated through shattered windows in the Vector building by the shock wave of the explo$\operatorname{sion}^{69}$ and a need for preparedness. Koltsovo, where the 
explosion occurred is in the Southern part of Russia, bordering China, Mongolia and Kazakhstan and less than $2500 \mathrm{~km}$ from Jammu and Kashmir in India. Health system capacity for detecting unusual epidemics early and responding as rapidly as possible is critical. A rapid and well-coordinated response will require both physical space for case isolation and quarantine of contacts, as well as health workers and personnel for contact tracing and for accomplishing vaccination drives. ${ }^{9}$ While India has the potential for large the surge in personnel, this will require protection of health workers and incentivisation of community volunteers to conduct contact tracing and case finding. Enough vaccine should be reserved for the health workforce, as well as for community volunteers. During smallpox eradication, India was the most challenging setting, with the failure of mass vaccination attempts. ${ }^{70}$ When the strategy was switched to contact tracing and ring vaccination, community volunteers were paid financial incentives. ${ }^{17}$ This approach may be required in the event of smallpox re-emergence in India. The first Biosecurity Level (BSL) 4 laboratory in India, established in Pune, will enhance capacity for diagnostics and surveillance. A review of smallpox vaccine stockpiles and manufacturing capacity is also important. This study also has lessons for COVID-19 vaccination in India, as the incubation period is similar and it is also caused by a respiratory transmissible virus.

Limitations of this study include unavailability of some data, such as age-specific rates of organ transplants and autoimmune diseases for the Indian population. The agespecific distributions from other countries were adapted for India (such as incidence data of rheumatoid arthritis) to distribute organ transplants and autoimmune diseases for estimation of immunosuppression. ${ }^{27}$ However, we still used a minimum estimate of the immunosuppressed population and did not include diseases such as diabetes, malaria or the presence of malnutrition, all of which are highly prevalent in India and would worsen the impact of an epidemic. The contact matrix was derived from a study which estimated the age-specific contact rates for India. ${ }^{4}$ We estimated $70 \%$ of people over the age of 40 in India were vaccinated against smallpox before $1977 .{ }^{172044}$ However, there is uncertainty around the degree of the waning of vaccine immunity. ${ }^{17}$ Finally, we looked at a large, densely populated city, Mumbai and studied the epidemic consequences. This may not be generalisable to other parts of India, as almost $70 \%$ of the population of India lives in rural areas and small towns where the transmission would be less intense because of lower population density. However, healthcare facilities, diagnostics and health workers are in short supply in rural areas. ${ }^{71} 72$ Further limitations are the lack of consideration of seasonality in the virus transmissions and vaccine refusal. We did not set a particular time of the year for the scenario tested, however, smallpox transmission varies with season and is most likely enhanced by dry weather. ${ }^{73}$ This could influence the outcomes of a smallpox outbreak in India, where there is only a dry and wet season. Regarding vaccine refusal, we did not account for this parameter in our study, although many recent outbreaks of vaccinepreventable diseases have been linked to under vaccinated communities. ${ }^{74}$ However, in India, accessibility due to long distances from healthcare facilities is the main factor linked to under-vaccination, but the level of vaccine acceptance is found to be still high, ${ }^{75}$ with only $16 \%$ of the vaccine-hesitant people refusing vaccination. ${ }^{76}$

Finally, for this study, we tested the sensitivity of results to variations in parameters involved in the public health response, such as contacts traced and cases isolated, time to start the intervention and number of doses delivered each day. This helps inform policy making for the most effective response within limited resources. However, we acknowledge that we could not vary every parameter involved and this can represent a further limitation.

\section{CONCLUSION}

In summary, we have shown a range of possible scenarios of re-emergent smallpox in Mumbai. Speed of response, stockpiling, vaccination, human resources for health and physical space for smallpox treatment and isolation are all influential factors. This study tells us that if smallpox reemergence occurs, it may have significant health and economic impact, the extent of which will depend on the availability and delivery of interventions such as a vaccine or antiviral agent, where these are needed the most, and the capacity of case isolation and treatment. Further research on health systems requirements and capacity across the diverse states and territories of India, across public and private health systems and inter-sectoral engagement especially the involvement of the community, could improve the preparedness and management strategies in the event of re-emergent smallpox or other serious emerging infections.

Contributors CRM designed the study and developed the research questions, supervised the research, drafted and revised the manuscript, gave final approval of the manuscript. VC participated in the literature review and study development, developed research questions, modelling analysis and drafted and revised the manuscript. BM conducted a literature review, collected the data, performed modelling analysis and drafted and revised the manuscript. AAC helped with the development of the study, participated in the literature review and manuscript drafting and revision. JN participated in the literature review, study development, drafted and revised the manuscript. AD collected the data, participated in the literature review and drafted the manuscript.

Funding Raina Maclntyre is supported by a NHMRC Principal Research Fellowship, grant number 1137582.

Competing interests None declared.

Patient consent for publication Not required.

Provenance and peer review Not commissioned; externally peer reviewed.

Data availability statement All data relevant to the study are included in the article or uploaded as supplemental information. All data used in this study are publicly available online and listed in the references.

Supplemental material This content has been supplied by the author(s). It has not been vetted by BMJ Publishing Group Limited (BMJ) and may not have been peer-reviewed. Any opinions or recommendations discussed are solely those of the author(s) and are not endorsed by BMJ. BMJ disclaims all liability and responsibility arising from any reliance placed on the content. Where the content 
includes any translated material, BMJ does not warrant the accuracy and reliability of the translations (including but not limited to local regulations, clinical guidelines, terminology, drug names and drug dosages), and is not responsible for any error and/or omissions arising from translation and adaptation or otherwise.

Open access This is an open access article distributed in accordance with the Creative Commons Attribution Non Commercial (CC BY-NC 4.0) license, which permits others to distribute, remix, adapt, build upon this work non-commercially, and license their derivative works on different terms, provided the original work is properly cited, appropriate credit is given, any changes made indicated, and the use is non-commercial. See: http://creativecommons.org/licenses/by-nc/4.0/.

\section{ORCID iDs}

Valentina Costantino http://orcid.org/0000-0001-6017-4430

C Raina Maclntyre http://orcid.org/0000-0002-3060-0555

\section{REFERENCES}

1 Parida M, Dash PK, Kumar JS, et al. Emergence of influenza A (H1N1)pdm09 genogroup 6B and drug resistant virus, India, January to May 2015. Euro Surveill 2016;21:6-11.

2 SPHCM. Infectious disease blog: infectious disease outbreaks in India- challenges and opportunities, 2016. Available: https://sphcm. med.unsw.edu.au/infectious-diseases-blog/infectious-diseaseoutbreaks-india-challenges-and-opp

3 Adam DC, Scotch M, Maclntyre CR. Phylodynamics of influenza $\mathrm{A} / \mathrm{H} 1 \mathrm{~N} 1 \mathrm{pdm09}$ in India reveals circulation patterns and increased selection for clade $6 \mathrm{~B}$ residues and other high mortality mutants. Viruses 2019;11:791.

4 Prem K, Cook AR, Jit M. Projecting social contact matrices in 152 countries using contact surveys and demographic data. PLoS Comput Biol 2017;13:e1005697.

5 WHO. "Smallpox", 2020. Available: https://www.who.int/healthtopics/smallpox\#tab=tab_1

6 Henderson DA, Arita I. The smallpox threat: a time to reconsider global policy. Biosecur Bioterror 2014;12:117-21.

7 Adam DC, Scotch M, Maclntyre CR. Bayesian phylogeography and pathogenic characterization of smallpox based on HA, ATI, and crmB genes. Mol Biol Evol 2018;35:2607-17.

8 Maclntyre CR, Heslop DJ, Nand D, et al. Exercise Mataika: white paper on response to a smallpox bioterrorism release in the Pacific. Global Biosecurity 2019;1:91

9 Maclntyre CR, Costantino V, Mohanty B, et al. Epidemic size, duration and vaccine Stockpiling following a large-scale attack with smallpox. Global Biosecurity 2019;1:74.

10 Frank F, Henderson Donald A, Isao A, et al. Smallpox and its eradication / F. Fenner . [et al.][: World Health Organization, [1988. https://apps.who.int/iris/handle/10665/39485

11 CDC. Smallpox: for clinicians, 2016. Available: https://www.cdc.gov/ smallpox/clinicians/transmission.html

12 CDC. History of smallpox, 2016. Available: https://www.cdc.gov/ smallpox/history/history.html

13 Bala P. Medicine and the Raj: British medical policy in India, 1835-1911 (review). Bull Hist Med 2000;74:840-1.

14 Basu RN. Smallpox eradication: lessons learnt from a success story. Natl Med J India 2020;19:33-6.

15 Hopkins DR. Expunging variola: the control and eradication of smallpox in India 1947-1977. JAMA 2007;297:2287.

16 Bazin $\mathrm{H}$. Vaccination: a history from lady Montagu to genetic engineering, 2020. Available: https://books.google.com.au/books? $\mathrm{id}=$ orjaA_7sYZQC\&printsec $=$ copyright\&redir_esc $=y \# v=$ onepage\&q\& $\mathrm{f}=$ false

17 Lahariya C. A brief history of vaccines \& vaccination in India. Indian J Med Res 2014;139:491-511.

18 Encyclopaedia Britannica. Dyarchy British India government system. Available: https://www.britannica.com/topic/dyarchy

19 Wikipedia. Government of India act 1919, 1919. Available: https://en. wikipedia.org/wiki/Government of India Act 1919

20 Bowles C. Smallpox research in India. Am J Nurs 1961;61:92-3.

21 Kretzschmar M, van den Hof S, Wallinga J, et al. Ring vaccination and smallpox control. Emerg Infect Dis 2004;10:832-41.

22 Ryan KJ, Ray CG. Sherris medical microbiology. 4th ed. New York, USA: McGraw Hill, 2004: 525-8.

23 Massung RF, Knight JC, Esposito JJ. Topography of variola smallpox virus inverted terminal repeats. Virology 1995;211:350-5.

24 Massung RF, Loparev VN, Knight JC, et al. Terminal region sequence variations in variola virus DNA. Virology 1996;221:291-300.

25 CDC. "What is smallpox?", 2017. Available: https://www.cdc.gov/ smallpox/about/index.html
26 Riedel S. Edward Jenner and the history of smallpox and vaccination. Proc 2005;18:21-5.

27 Maclntyre CR, Costantino V, Chen X, et al. Influence of population immunosuppression and past vaccination on smallpox reemergence. Emerg Infect Dis 2018;24:646-53.

28 Maclntyre CR, Costantino V, Kunasekaran MP. Health system capacity in Sydney, Australia in the event of a biological attack with smallpox. PLoS One 2019;14:e0217704.

29 CDC. Smallpox vaccine basics: who should get vaccination, 2017. Available: https://www.cdc.gov/smallpox/vaccine-basics/who-getsvaccination.html

30 Eichner M. Analysis of historical data suggests long-lasting protective effects of smallpox vaccination. Am J Epidemiol 2003;158:717-23.

31 Rao AR. Smallpox. Bombay, India: Kothary B depot, 1972. https:// www.nlm.nih.gov/nichsr/esmallpox/rao.pdf

32 Breman JG, Henderson DA. Diagnosis and management of smallpox. N Engl J Med 2002;346:1300-8.

33 Inflibnet. Chapter III: Hospital industry, 2013. Available: http:// shodhganga.inflibnet.ac.in/bitstream/10603/40985/14/14_chapter\% 203.pdf

34 Maclntyre CR, Costantino V, Chen X, et al. Influence of population immunosuppression and past vaccination on smallpox reemergence. Emerg Infect Dis 2018;24:646-53.

35 Costantino V, Kunasekaran M, Maclntyre CR. Modelling of optimal vaccination strategies in response to a bioterrorism associated smallpox outbreak. Human Vaccines \& Immunotherapeutics KHVI 2020.

36 WHO. Summary report on first, second and third generation smallpox vaccines, 2013. Available: https://www.who.int/immunization/sage/ meetings/2013/november/2_Smallpox_vaccine_review_updated_11 10 13.pdf?ua=1

37 Yen C, Hyde TB, Costa AJ, et al. The development of global vaccine stockpiles. Lancet Infect Dis 2015;15:340-7.

38 World Population Review. Mumbai population, 2019. Available: http:// worldpopulationreview.com/world-cities/mumbai/

39 Census India. C-14 five year age group data by residence and sex, 2019. Available: http://www.censusindia.gov.in/2011census/C-series/ C-14.html

40 The World Bank. World development indicators: health systems, 2017. Available: http://wdi.worldbank.org/table/2.12

41 Chaudhari A, Mazumdar K, Motwani Y, et al. A profile of occupational stress in nurses. Annals of Indian Psychiatry 2018;2:109.

42 Forum for Improving Quality of Services in Mumbai Suburbs. About Mumbai suburbs: health, 2001. Available: http://www.forum4iqolms. org/about mumbai.html

43 Understanding our Civic issues: Health services in Mumbai. The Bombay community public trust, 2014. Available: http://www.bcpt. org.in/articles/healthservices.pdf

44 The Wikipedia. 1974 smallpox epidemic in India, 2018. Available: https://en.wikipedia.org/wiki/1974 smallpox epidemic in India

45 NACO. HIV Facts \& figures. National AIDS control organisation, MoHFW, Gol, 2018. Available: http://naco.gov.in/hiv-facts-figures

46 World Bank. Hiv/Aids in India, 2012. Available: http://www. worldbank.org/en/news/feature/2012/07/10/hiv-aids-india

47 Rajpal S, Kumar A, Joe W. Economic burden of cancer in India: evidence from cross-sectional nationally representative household survey, 2014. PLoS One 2018;13:e0193320.

48 Sarveswaran G, Sakthivel MN, Krishnamoorthy Y, et al. Knowledge, attitude, and practice regarding organ donation among adult population of urban Puducherry, South India. J Educ Health Promot 2018;7:117

49 UNOS. Transplant trends: transplant by age of recipient. United network for organ sharing, 2018. Available: https://unos.org/data/ transplant-trends/transplants-by-age-of-recipient/

50 Kumar P, Ram U. Patterns, factors associated and morbidity burden of asthma in India. PLoS One 2017;12:e0185938.

51 Jindal SK, Aggarwal AN, Gupta D, et al. Indian study on epidemiology of asthma, respiratory symptoms and chronic bronchitis in adults (INSEARCH). Int $J$ Tuberc Lung Dis 2012;16:1270-7.

52 Cooper GS, Bynum MLK, Somers EC. Recent insights in the epidemiology of autoimmune diseases: improved prevalence estimates and understanding of clustering of diseases. J Autoimmun 2009;33:197-207.

53 Kedia S, Ahuja V. Epidemiology of inflammatory bowel disease in India: the great shift East. Inflamm Intest Dis 2017;2:102-15.

54 Malaviya AN, Singh RR, Singh YN, et al. Prevalence of systemic lupus erythematosus in India. Lupus 1993;2:115-8. 
55 Paul R, Raychaudhuri P, Sinha PK, et al. Prevalence of systemic lupus erythematosus among patients of hypothyroidism in a tertiary care center. Indian J Endocrinol Metab 2012;16:569.

56 Telegraph India. The rise of the killer cells - Telegraph India, 2020. Available: https://www.telegraphindia.com/7-days/the-rise-of-thekiller-cells/cid/1314168

57 Bagcchi S. Hypothyroidism in India: more to be done. Lancet Diabetes Endocrinol 2014;2:778.

58 Dogra S, Yadav S. Psoriasis in India: prevalence and pattern. Indian J Dermatol Venereol Leprol 2010;76:595.

59 Vora RV, Patel BB, Chaudhary AH, et al. A clinical study of vitiligo in a rural set up of Gujarat. Indian J Community Med 2014;39:143-6.

60 Rheumatoid Arthritis. RA statistics, 2013. Available: https:// rheumatoidarthritis.net/what-is-ra/ra-statistics/

61 Carbonell J, Cobo T, Balsa A, et al. The incidence of rheumatoid arthritis in Spain: results from a nationwide primary care registry. Rheumatology 2008;47:1088-92.

62 Eichner M, Dietz K. Transmission potential of smallpox: estimates based on detailed data from an outbreak. Am J Epidemiol 2003;158:110-7.

63 Stockdale JE, Kypraios T, O’Neill PD. Modelling and bayesian analysis of the abakaliki smallpox data, 2016. Available: https://arxiv. org/abs/1605.07924

64 USAMRIID-United States Army Medical Research Institute of Infectious Diseases. Medical management of biological casualties handbook. 8th edition, 2014. https://www.usamriid.army.mil/ education/bluebookpdf/USAMRIID BlueBook 8th Edition - Sep 2014. pdf

65 Nishiura H, Eichner M. Infectiousness of smallpox relative to disease age: estimates based on transmission network and incubation period. Epidemiol Infect 2007;135:1145-50.

66 Population Pyramid. India 2017, 2017. Available: https://www. populationpyramid.net/india/2017/
67 Maclntyre R. The risk of selective investment in downstream pandemic planning. Global Biosecurity 2019;1:85.

68 Aljazeera. India's healthcare: private vs public sector, 2017. Available: https://www.aljazeera.com/indepth/interactive/2017/08/indiahealthcare-private-public-sector-170831125534448.html

69 Maclntyre CR, Doolan C, De Sllva C. The explosion at vector: hoping for the best while preparing for the worst. Global Biosecurity 2019;1:91-4.

70 University of Michigan Library. Smallpox eradication in India, 19721977, 2018. Available: https://www.lib.umich.edu/online-exhibits/ exhibits/show/smallpox-eradication-india/indian-engages-pandemic/ smallpox-in-india

71 Das S, Patro KC. Cancer care in the rural areas of India: a firsthand experience of a clinical oncologist and review of literatures. $J$ Cancer Res Ther 2010;6:299.

72 Banavali SD. Delivery of cancer care in rural India: experiences of establishing a rural comprehensive cancer care facility. Indian J Med Paediatr Oncol 2015;36:128-31.

73 Nishiura H, Kashiwagi T, Smallpox KT. Smallpox and season: reanalysis of historical data. Interdiscip Perspect Infect Dis 2009;2009:1-10.

74 Dubé E, Vivion M, MacDonald NE. Vaccine hesitancy, vaccine refusa and the anti-vaccine movement: influence, impact and implications. Expert Rev Vaccines 2015;14:99-117.

75 Sharma S, Akhtar F, Singh RK, et al. Understanding the three as (awareness, access, and acceptability) dimensions of vaccine hesitancy in Odisha, India. Clin Epidemiol Glob Health 2020;8:399-403.

76 Larson HJ, Schulz WS, Tucker JD, et al. Measuring vaccine confidence: introducing a global vaccine confidence index. PLoS Curr 2015;7. doi:10.1371/currents.outbreaks. ce0f6177bc97332602a8e3fe7d7f7cc4. [Epub ahead of print: 25 Feb 2015] 